\title{
A Qualitative Study Inquiry among Patients with Diabetic Foot Ulcers: What have They Felt?
}

\author{
Kusnanto Kusnanto ${ }^{1 *(\mathbb{D})}$, Mohamad Alfaqih ${ }^{1}$, Padoli Padoli $^{2}$ (D) Hidayat Arifin $^{3}$ (D) \\ ${ }^{1}$ Department of Advance Nursing, Faculty of Nursing, Universitas Airlangga, Surabaya, Indonesia; ${ }^{2}$ Politeknik Kesehatan \\ Kementerian Kesehatan Surabaya, Surabaya, Indonesia; ${ }^{3}$ Department of Medical Surgical Nursing, Faculty of Nursing, \\ Universitas Padjadjaran, Bandung, Indonesia
}

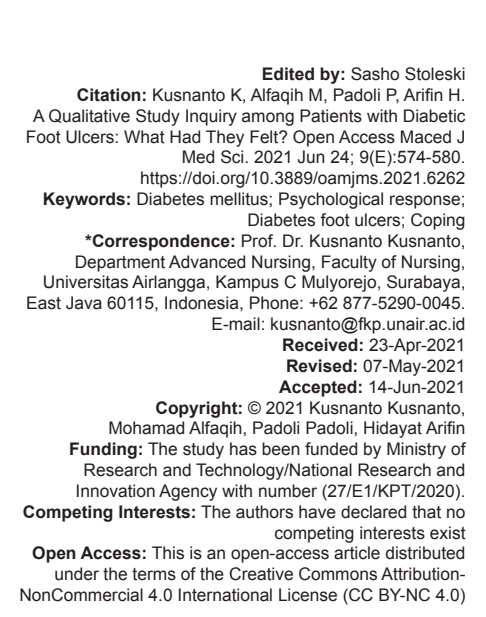

\section{Abstract}

BACKGROUND: Diabetic foot ulcers (DFU) caused physical and psychosocial problems and the risk of amputations and death.

\begin{abstract}
AIM: The aim of the study was to overview the feelings of diabetes mellitus patients with DFU.
\end{abstract}
METHODS: A phenomenological qualitative study design was undertaken from January to April 2020. A total of 25 patients with DFU were determined through the purposive sampling technique. The study was conducted among the patients undertaking home-based wound care in Bojonegoro, Indonesia. The proposed discussion guidelines were used to collect the data through in-depth interviews. Colaizzi's technique was used to analyze the data and it was managed by NVIVO.

RESULTS: We emerged two themes: Psychological and physiological response of patients with DFU and coping mechanisms in caring DFU. Among the patients with DFU, we determined their psychological responses and coping mechanisms as reported in this study.

CONCLUSIONS: Patients with DFU are expected to be able to control themselves psychologically. Health workers such as doctors and nurses can provide interventions by considering the psychological condition of patients with DFU. A good psychological condition can ensure that their blood sugar is regulated properly.

\section{Introduction}

Diabetic foot ulcers (DFU) can have an impact on the individual's responses related to the disease process and healing [1]. The response depends on their perception of the disease, its severity, the environmental factors, and the level of family support. The response that often occurs is the existence of fear and anxiety due to the stress experienced by the individual. Complications in the form of diabetic ulcers can have an impact on the individual responses related to the disease process and healing [2]. All of these aspects make the patient feel frustrated, dissatisfied, insecure, fearful, helpless, and not in control. Individuals with injuries feel unable to carry out their daily activities and often consider themselves unable to play their role in society [3]. Poor healing in patients with diabetic ulcers will create multiple burdens for the patient including morbidity, distress, and the disruption of functional abilities that ultimately increase their costs due to prolonged care and treatment. This can trigger increased stress levels in patients with diabetic ulcers [4]. Each patient builds their own experience of the disease which includes emotional and cognitive aspects. These, in turn, will determine the coping strategies used. The right coping strategy plays an important role in the physical and psychological health of the patient [5].

The World Health Organization states that the prevalence of diabetes mellitus (DM) worldwide is estimated to be $9 \%$. In 2030 , it is estimated that DM will rank as the $7^{\text {th }}$ cause of death in the world [6]. Patients with diabetes in Indonesia aged $\geq 15$ years total $6.9 \%$ of the population with an estimated absolute number of 12 million people. Nearly $50 \%$ of people with diabetes experience diabetic ulcers with a mortality rate of $8-35 \%$, and among them, $15-30 \%$ have amputations [7]. The International Diabetes Federation predicts an increase in the number of people with diabetes in Indonesia from 9.1 million in 2014 to 14.1 million in 2035. DM sufferers in East Java, Indonesia total $2.1 \%$ or 605,974 people, with $35 \%$ of them having diabetic ulcers [8].

DFU is caused by prolonged blood sugar instability that affects the peripheral blood vessels and the nervous system [9]. The conditions for DFU that take a long time to heal can result in a deterioration of the patient's psychological condition. On the other 
hand, psychological disorders can worsen their blood sugar condition and make it poorly regulated [10]. In conditions of stress and psychological disturbances, the release of insulin and glucagon is disrupted. This can result in an increased blood sugar level. Patients with DFU experience being afraid of losing their feet and have difficulties coping with the situation [11]. Patients expect the health professionals to understand the difficulties that they are experiencing. The management of DFU needs to involve supportive interactions with health professionals, financial support from their health insurance, and the lessening of their burden due to the responsibilities of the healthcare setting [12].

DFU are a frequent complication of DM with subsequent disturbances in the daily life of the patients. The co-existence of depression and anxiety among diabetic foot patients is a common phenomenon and the role of each in perpetuating the other is highlighted in the literature [12], [13]. Appropriate interventions with personal and interpersonal approaches are needed to overcome the depression and anxiety experienced by DM sufferers with DFU. For this reason, this study aims to overview the feelings of DM patients with DFU through a qualitative approach that can be used as basic information for the construction of further interventions.

\section{Methods}

\section{Study design}

A qualitative phenomenology study design was undertaken in the period January to April 2020.

\section{Participant selection and setting}

In this study, 25 DM patients with DFU were recruited using a purposive sampling technique. The participants in this study were active DM patients who conducted wound care at home in Bojonegoro, Indonesia. The participants were subjected to a faceto-face approach in this research. During the research process, no participants dropped out, and they were able to follow the research through until it was completed. The participants in this study were given coding known only to the researcher. In addition, the research data including recordings and field notes were kept by the researcher strictly for research purposes. This research was conducted at a hospital for wounds in Bojonegoro, Indonesia. The interview process was carried out in a separate room to the treatment room. This was to maintain confidentiality and provide comfort. The inclusion criteria in this study were respondents who were over 40 years old who were able to communicate verbally well, who had suffered from DFU for at least 4 weeks, and who were undergoing DFU treatment.
Participants who could not attend the study until completion were excluded from the study.

\section{Data collection}

The interview guidelines are made and developed by the researchers. The questions in the interview covered their feelings, stress, and the expectations of DM patients with DFU. All questions were open-ended. The triangulation methods used in this study were methodological triangulation and researcher triangulation consisting of a multi-method approach to one problem. Methodological triangulation data collection using various methods includes interviews, recordings, and field notes. The in-depth interview process was carried out for 30-40 min for one interview. In this study, the interview process was repeated 2-3 times to reach the point of saturated data and individual information. The transcripts of the interview results were analyzed and returned to the participants to be checked regarding their suitability as part of the interview process [14]. The researcher kept the research data for 3 months until the research process was completed. To delete the research data, the researcher submitted a request to the Health Services Ethics Commission and was approved. Their trustworthiness was supported in this study through the use of the guidelines developed by Lincoln and Guba [15] related to credibility, dependability, confirmability, and transferability.

\section{Analysis}

The process of organizing coding data is assisted by the NVIVO 12 software (QSR International) for coding and organizing the data. The analysis of the interview results used Colaizzi's technique. The stages consisted of (1) familiarization with the transcript, (2) identifying significant statements, (3) formulating the meanings, (4) clustering the themes, (5) developing an exhaustive description, (6) producing the fundamental structure, and (7) seeking verification of the fundamental structure [16].

\section{Ethical considerations}

This research has been declared to be ethical by the Health Services Ethics Commission of the Faculty of Nursing of Universitas Airlangga in Surabaya, Indonesia, certificate number No.1947-KEPK.

\section{Results}

This study involved 25 DM patients undergoing diabetic ulcer wound treatment. The number of 
participants was determined by the saturation of the data obtained from the analysis of the participants' answers. There were two themes found in this study. The themes that emerged include the patient's psychological and physiological response of patients with DFU and coping mechanisms in caring DFU.

Theme 1: Psychological and physiological response of patients with DFU

The patients had cognitive, emotional, physiological, and behavioral responses. Among the responses, physiological responses and emotional responses were the ones often complained about by the participants as disrupting all aspects of their life.

The cognitive responses of the DM patients who undergo diabetic ulcer treatment are about their experience, knowledge, and thought patterns.

\section{a. Experience}

The participants had unpleasant experiences and disrupted activities when experiencing diabetic ulcers. The participant's experience category was supported by one participant statement as follows:

"The experience is not good, you can't do activities as usual. Usually I go shopping to cook, sweep the house, now I can't do anything, I just lie down at home. It's not good, bro, it's not all good, anyway, can't do activities as usual. Usually, it can go anywhere. Now at the knock house. Cannot go to the fields, look at the term." (P3).

"This is the second wound. At first, I didn't know the blisters were suddenly like that, then I took them to the hospital, he said he wanted surgery, how come it turned out like this, the wound was small at first, bro, not like now The doctor said I wanted to be operated on, so I just complied, I didn't know it was like this "and this is a dangerous disease" (P4)

\section{b. Knowledge}

The participants have varied knowledge of diabetic ulcers. The categories of participant knowledge are supported by one participant statements as follows:

"This wound disease is due to diabetes. Yes, actually everyone has the potential to experience this disease. Because we don't regulate our diet and lifestyle. This is a very heavy and dangerous wound" (P9).

The emotional reactions felt by the participants include the negative feelings when they were first exposed to DM and ulcers. The negative feelings felt were anxiety, fear, and depression when they experienced diabetic ulcers. This follows the theory presented in this study.

\section{a. Negative feelings}

The participants have sad emotional reactions to diabetic ulcers. The categories of sadness, anxiety, and fear among the participants are supported by one participant's statement as follows:

"At first it was sad, how come I got injured. When I got this wound, I got sadder, I was afraid if I couldn't heal. I'm anxious and afraid, I don't understand if you have diabetes, even though you're still 40 years old, how come it be. I didn't do anything, but suddenly I get injure (P6).

The physiological responses experienced by the participants include disorders of the urinary system, disorders of the digestive system, and disorders regarding peripheral tissue perfusion. When faced with stress, the body mobilizes itself to deal with that stress.

\section{a. Urinary system}

The participants experienced a physiological reaction, including urinary system disorders, when experiencing DM. The category of urinary system disorder among the participants is supported by one participant's statement as follows:

"Frequent urination, I felt like urinating all the time, and it often happened at night"(P23).

\section{b. Digestive system}

The participants experienced a physiological reaction, namely, digestive system disorders, when experiencing DM. The category of digestive system disorders is supported by one participant's statement as follows:

"Before I got diabetes, I often ate, snacked, I couldn't help but feel lost, bro. At nights when you're hungry, eat. I'm often hungry, but I can't stand it at night" (P4).

\section{c. Perfusion system}

The participants experienced a physiological reaction, namely, the disruption of the peripheral tissue perfusion system, when experiencing DM and diabetic ulcers. The category of tissue perfusion system disorders among the participants is supported by one participant's statement as follows:

"Yes, I feel weak, like numbness, being weak, can't do anything. It's not good, feel so weak. It hurts all body" (P8). 


\section{Theme 2: Coping Mechanism in Caring DFU}

Maintaining the daily patterns of life and maintaining a regular eating pattern is an effort made by the patients when dealing with DM and when undergoing treatment for diabetic ulcers. This is also the main strategy of the patients in the process of healing diabetic ulcers. However, in this study, no isolation method of coping was found caused by the patients' depression. The physical and social impacts are the most important in the lives of DM patients undergoing treatment for DFU. The feeling of anxiety when carrying out worship activities also affects the spiritual aspect of the patient. Hope is a basic form of trust that the patients want to experience change in the future. One source of support is the support system that the patients have when undergoing treatment for diabetic ulcers. While healing is the main priority, it is expected by the patients for them to be able to carry out activities as before and to get a better quality of life.

Confrontative coping describes attempts to aggressively change a situation or problem, describing the level of anger and taking risks. A coping mechanism can be constructive if it leads to problem-solving, but it can also be destructive if the feelings of stress are expressed negatively and aggressively.

\section{a. Diet}

The participants made an effort to adjust their diet when experiencing diabetic ulcers. The information on the diet of the participants is supported by one participant's statement as follows:

"My blood sugar was 400 at that time, then I didn't adjust it right away, I used to eat sweet foods, snacking at night. I used to eat sweet foods. Anyway, when I know high blood sugar, I reduce the portion of food, now I eat 1 spoon and tofu. I now also maintain my diet because I saw it on YouTube, he said, try not to eat too much rice, now I don't eat white rice anymore, I eat brown rice, vegetables, egg white. (P21)

\section{b. Pattern of life}

The participants made an effort to maintain their lifestyle when experiencing diabetes and diabetic ulcers. The lifestyle categories of the participants are supported by one of the participant's statements as follows:

"Yes, we use my own herbal medicine, I process it myself, I know from a neighbor, I also often check with the doctor every month. I immediately took the herbal mas ginger, ginger, and turmeric, often bought by my children." (P25).

"I have also used leech therapy in the Malang area, bro. Indeed, after the leech therapy, it tastes good, it's like numbness, then the leeches suck the blood like smooth (P19)
Compromise describes the effort undertaken to change the situation carefully, including asking for help and cooperation from their family and coworkers or reducing their desires and choosing the middle way. This changes the ineffective methods of acting, changing their goals, and sacrificing aspects of their personal interests.

\section{a. Strategy}

All of the participants have a strategy or way of dealing with diabetes and diabetic ulcers. The strategic categories of participants are supported by one participant's statements as follows:

"I was escorted by my child to the hospital, in the hospital for only 3 days I asked to go home because I didn't feel at home, then my child was ordered to be treated at the place, the problem was the previous wound was there too. First, I took it to Prambon, and Soko, that's the nurses at my house. But it didn't matter, I continued to take it to another orderly, but I only gave the medicine, I didn't treat it" (P12).

\section{b. Adaptation}

The participants have made an effort to adapt to DM and diabetic ulcers. The adaptation categories of the participants are supported by one participant statement as follows:

"Control to the general practitioner. When I feel uncomfortable, I take it to the community health center. Anyway, when I know high blood sugar, I immediately drink herbal medicine, eat something weird, snacking doesn't reduce" (P13).

\section{Discussion}

Diabetic ulcers are a major health problem in society because of their adverse effects on physical health, psychosocial functioning, and the increased risk of recurrence of diabetic injuries, amputation, and death. Diabetic ulcers have an impact on the individual's biological, psychological, sociological, and spiritual responses in relation to the process of disease and healing. DM patients undergoing ulcer wound care have different responses and coping mechanisms. Their psychological, physical, and emotional responses are the most influential. The domain of negative emotional responses includes feelings of sadness and fear of a more severe impact, including their health problems not being cured. The physical response domains include digestive system disorders, urinary system disorders, and tissue perfusion system disorders. The coping mechanism domain or efforts made to deal with the 
condition of the disease include confrontational coping and compromising coping, namely, by maintaining their lifestyle and diet. This becomes an adaptation strategy used by the patients to continue to undergo the process of healing, care, and treatment. Anxiety and depression are common among diabetic foot wound patients [13].

This can be influenced by several internal and external factors. One of the internal factors is the knowledge, experience, and acceptance response of the participants. The external factors include the wound care obtained. The impact of the disease that is most felt by the DM patients undergoing treatment for diabetic ulcer wounds refers to the physical and social impacts, as it affects all aspects of the patient's life. Healing is the main priority expected by DM patients undergoing treatment for diabetic ulcer wounds so then they can carry out activities as before and get a better quality of life. Studies conducted in Indonesia related to the patient's psychological response and coping mechanisms specifically among those undergoing treatment for DM ulcer wounds have been rarely undertaken. This study aimed to explore the psychological response and coping mechanisms of DM patients undergoing DM ulcer treatment to understand how the types of responses and coping mechanisms impact on DM.

The emotional reactions felt by the participants were negative. This follows the theory that the dominance of negative emotions such as anxiety, depression, and anger is an indication that the individual judges the situation to be something that causes stress [17]. The situation is felt to hurt or harm (harm/loss) them, or it involves a threat that can arise, injure or harm the individual's existence. Anxiety and depression are common among those with diabetic foot wounds [13]. This can be influenced by several factors, both internal, and external. One of the internal factors is the knowledge, experience, and acceptance response from participants. External factors include the wound care obtained. The participants' knowledge about DM and diabetic ulcers is that the participants think that diabetes is a dangerous disease and can cause death. The higher a person's knowledge level is, the more this will affect the wound healing process, wound prevention and the efforts made, and vice versa. A low level of education can negatively affect the quality of the information that is collected [3].

People with diabetes and diabetic ulcers experience different disease pathways that can affect health-related behavior. Education aimed at improving foot care behavior and health outcomes in the feet should be adapted to the specific disease scheme associated with peripheral neuropathy [18]. A lack of control in DM patients who experience diabetic ulcers raises a series of negative emotions such as fear and worry which can affect the development of DFU [19]. However, on the other hand, the previous research states that patients with DFU and diabetes have a very strong feeling of helplessness [3]. This feeling is significantly stronger when they experience diabetic ulcer wounds or foot ulcers. The incidence of depression and depressive symptoms in DM patients who experience ulcer wounds can be a barrier to exercise. DFU patients who are depressed are significantly more likely to be physically inactive, and those who are physically inactive are more likely to experience depression or have increased depressive symptoms [20].

Another research that conducted by Paton et al., 2014 about the patients' experience with therapeutic footwear while living with the risk of neuropathic DFU explains that there are several perceptions such as the self-perception dilemma, the adherence response, the reflective adaption, and reality appraisal [21]. Another study conducted by Chithambo in 2015 that explored the factors that contribute to a delay in seeking help with diabetes-related foot problems refers to the level of prior foot care information, the patient's awareness of the foot problem, the ability to perform foot care behaviors on ulcer presentation, the perception of the risk competing for priorities, and the use of selfmanagement strategies for the foot problem, the presence of specific help-seeking triggers comorbid conditions, concurrent illness, and delayed secondary referrals [22].

Diabetic ulcers can have an impact on the individual responses related to the disease process and the healing of the disease itself. There are several types of impact experienced by the DM patients who undergo diabetic ulcer treatment including the physical impacts, social impacts, and spiritual impacts. The physical impact felt by DM patients is weakness and pain in the wound. The social impact felt by DM patients who undergo diabetic ulcer treatment is limited activity and the disruption of work while the spiritual impact experienced is a disruption of the implementation of worship activities. Physical and social impacts are the most important impacts in the lives of DM patients who undergo diabetic ulcer wound treatment. Psychological conditions such as depression, anxiety, and eating disorders are significantly higher among people with diabetes than in the general population [23]. The feeling of anxiety when carrying out worship activities also affects the spiritual aspect of the patient.

Diabetic ulcers have a profound impact on the patient, leading to lifestyle changes, chronic pain, low self-esteem, and depression. Living with chronic sores, which are often associated with an odor, exudation, edema, and pain, can produce a series of changes in the lives of the patients and their families. Tehey feel uncomfortable, discouraged, and helpless in the face of losing control of their own lives. The lesions can remove the patient from work and become a reason for the early retirement of an individual who is still in the productive stage of life due to the paralytic nature of the disease. The majority of the participants in this study have retired [13]. Patients who have foot ulcers 
experience social isolation, frequent pain in the wounds, and impaired physical functioning [24].

\section{Conclusion}

DM patients undergoing ulcer treatment have different responses and mechanisms. The psychological responses, physical responses, and emotional responses are the most influential. The majority of patients have DM with the additional complication of diabetic ulcers experience stress, depression, and anxiety. They need support from their family and social support network. They also have a financial burden and experience helplessness, blame themselves, and feel uncertain. This study has shown that coping styles and depression affecting the healing of diabetic ulcers. The healing of diabetic ulcers is determined by coping, confrontation, and compromise. This proves that the individual's coping mechanism determines the compliance process referring to the treatment of diabetic ulcers. Regarding the experience of patients with DFU, they must be able to adapt to a limited life. They must also have a good coping style and an adaptive response to survive and heal their diabetic ulcers.

By knowing the responses and coping mechanisms of patients with DFU, it is expected for all health workers and nurses to provide comprehensive nursing care not only for the biological aspect but also the psychological, social, cultural, and spiritual aspects as well. Treating patients with DFU comprehensively cannot only improve their quality of life but also improve their coping style and adaptive response.

\section{Availability of data and materials}

The datasets used and/or analyzed during the current study are available from the corresponding author on reasonable request.

\section{Acknowledgment}

We express our deepest gratitude to all respondents from the anti-vaccine and pro-vaccine communities and those who have helped this research.

\section{References}

1. Everett $\mathrm{E}$, Mathioudakis N. Update on management of diabetic foot ulcers. Ann N Y Acad Sci. 2018;1411(1):153-65. https://doi. org/10.1111/nyas. 13569

\section{PMid:29377202}

2. Maslakpak $M H$, Shahbaz A, Parizad N, Ghafourifard $M$ Preventing and managing diabetic foot ulcers: Application of Orem's self-care model. Int J Diabetes Dev Ctries. 2018;38(2):165-72. https://doi.org/10.1007/s13410-017-0570-5

3. De Almeida SA, Salomé GM, Dutra RA, Ferreira LM. Feelings of powerlessness in individuals with either venous or diabetic foot ulcers. J Tissue Viability. 2014;23(3):109-14. https://doi. org/10.1016/j.jtv.2014.04.005

\section{PMid:24882082}

4. Vedhara K, Miles JN, Wetherell MA, Dawe K, Searle A, Tallon D, et al. Coping style and depression influence the healing of diabetic foot ulcers: Observational and mechanistic evidence. Diabetologia. 2010;53(8):1590-8. https://doi.org/10.1007/ s00125-010-1743-7

PMid:20411235

5. Siersma V, Thorsen $\mathrm{H}$, Holstein PE, Kars M, Apelqvist J, Jude EB, et al. Diabetic complications do not hamper improvement of health-related quality of life over the course of treatment of diabetic foot ulcers-the eurodiale study. J Diabetes Complications. 2017;31(7):1145-51. https://doi.org/10.1016/j. jdiacomp.2017.04.008

PMid:28457703

6. World Health Organization. Global Status Report on Noncommunicable Diseases 2014. Geneva, Switzerland: World Health Organization; 2014. p. 176.

7. RI Kesehatan. Hasil Utama Riskesdas 2018. Indonesia: RI Kesehatan; 2018. p. 61.

8. Kemenkes RI. Situasi dan Analisis Diabetes. Indonesia: Pusat Data dan Informasi Kementerian Kesehatan RI; 2014. p. 2.

9. Kolluru GK, Bir SC, Kevil CG. Endothelial dysfunction and diabetes: Effects on angiogenesis, vascular remodeling, and wound healing. Int J Vasc Med. 2012;2012:1-30. https://doi. org/10.1155/2012/918267 PMid:22611498

10. Kalra S, Jena B, Yeravdekar R. Emotional and psychological needs of people with diabetes. Indian J Endocrinol Metab. 2018;22(5):696. https://doi.org/10.4103/ijem.ijem_579_17 PMid:30294583

11. Meriç M, Ergün G, Meriç $C$, Demirci İ, Azal Ö. It is not diabetic foot: It is my foot. J Wound Care. 2019;28(1):30-7. https://doi. org/10.12968/jowc.2019.28.1.30 PMid:30625047

12. Delea S, Buckley C, Hanrahan A, McGreal G, Desmond D, McHugh S. Management of diabetic foot disease and amputation in the Irish health system: A qualitative study of patients' attitudes and experiences with health services. BMC Health Serv Res. 2015;15(1):1-10. https://doi.org/10.1186/s12913-015-0926-9 PMid:26129712

13. Ahmad A, Abujbara M, Jaddou $H$, Younes NA, Ajlouni $K$. Anxiety and depression among adult patients with diabetic foot: Prevalence and associated factors. J Clin Med Res. 2018;10(5):411-8. https://doi.org/10.14740/jocmr3352w PMid:29581804

14. Cresswel J. Qualitative, Quantitative, and Mixed Methods Approaches. $5^{\text {th }}$ ed. Los Angeles: Sage Publications, Incorporated; 2013.

15. Lincoln YS, Guba EG. Naturalistic Inquiry. Newbury Park, California: SAGE Publications; 1985.

16. Morrow R, Rodriguez A, King N. Colaizzi's descriptive phenomenological method. Psychologist. 2015;28:643-4.

17. Folkman S, Lazarus RS. If it changes it must be a process : Study of emotion and coping during three stages of a college examination. J Pers Soc Psychol. 1985;48(1):150-70. 


\section{PMid:2980281}

18. Perrin BM, Swerissen H, Payne CB, Skinner TC. Cognitive representations of peripheral neuropathy and self-reported foot-care behaviour of people at high risk of diabetes-related foot complications. Diabet Med. 2014;31(1):102-6. https://doi. org/10.1111/dme.12287

PMid:23869945

19. Beattie AM, Campbell R, Vedhara K. What ever I do it's a lost cause. The emotional and behavioural experiences of individuals who are ulcer free living with the threat of developing further diabetic foot ulcers: Aqualitative interview study. Health Expect. 2014;17(3):42939. https://doi.org/10.1111/j.1369-7625.2012.00768.x

PMid:22429399

20. Bharara M, Rajpathak SN, Gunter MJ, Wylie-Rosett J, Ho GY, Kaplan RC, et al. The role of insulin-like growth factor-I and its binding proteins in glucose homeostasis and Type 2 diabetes. Diabetes Metab Res Rev. 2009;28(1):3-12. https://doi. org/10.1002/dmrr.919

PMid:19145587
21. Paton JS, Roberts A, Bruce GK, Marsden J. Patients' Experience of therapeutic footwear whilst living at risk of neuropathic diabetic foot ulceration: An interpretative phenomenological analysis (IPA). J Foot Ankle Res. 2014;7(1):1-9. https://doi. org/10.1186/1757-1146-7-16

PMid:24559125

22. Chithambo T, Forbes A. Exploring factors that contribute to delay in seeking help with diabetes related foot problems: A preliminary qualitative study using interpretative phenomenological analysis. Int Diabetes Nurs. 2015;12(1):20-6. https://doi.org/10. 1179/2057331615z.0000000006

23. NHS Diabetes. Emotional and Psychological Support and Care in Diabetes. United Kingdom: NHS Diabetes; 2010.

24. Umeh NI, Ajegba B, Buscetta AJ, Abdallah KE, Minniti CP, Bonham VL. The psychosocial impact of leg ulcers in patients with sickle cell disease: I don't want them to know my little secret. PLoS One. 2017;12(10):1-13. https://doi.org/10.1371/ journal.pone. 0186270

PMid:29045487 